\title{
Letter regarding the article of Jiao G. J. et al. entitled "Prognostic significance of cyclooxygenase-2 in osteosarcoma: a meta-analysis"
}

\author{
Shaozhong He • Zhenyu Xiao • Guangxuan Zeng • \\ Longhua Chen
}

Received: 11 April 2014 / Accepted: 29 April 2014 / Published online: 10 May 2014

(C) International Society of Oncology and BioMarkers (ISOBM) 2014

Dear Editor,

In a recent issue of Tumor Biology, Guangjun Jiao Wen and his workmates published an article [1] entitled "Prognostic significance of cyclooxygenase-2 in osteosarcoma: a meta-analysis." In this study, the investigators performed a meta-analysis to derive a precise estimate of the prognostic role of cyclooxygenase-2 (COX-2) expression in patients with osteosarcoma. The investigators concluded that osteosarcoma patients with high COX-2 expression were more closely associated with neoplasm metastasis and advanced clinical stage, and also have poor 3-year survival compared with those with low COX-2 expression. However, we have several opinions that we would like to raise to the investigators.

Firstly, the investigators had not focused specifically on the issue of the completeness of the search strategy report for databases. They just described the retrieval strategy by using combinations of keywords such as, "osteogenic sarcoma," "COX-2," "Cyclooxygenase-2," "prognosis," "prognostic," "marker," "survival," and "metastasis." We suggest that the investigators should provide us the details of the retrieval strategy and the flowchart of selection.

Secondly, 14 studies with a total of 735 osteosarcoma patients were included into the meta-analysis. In Table 1, the number of osteosarcoma patients in these studies [2-7] was less than the COX-2 positive numbers, respectively. We hope that the investigators could give us a reasonable explanation.

Thirdly, the investigators did not provide us any funnel plots for the Begg's test and the Egger's test. To strengthen the credibility of the meta-analysis, the investigators should provide us all these plots.

Finally, the investigators did not follow the metaanalysis of observational studies in epidemiology (MOOSE). As a minor suggestion, by adding MOOSE checklist, some summary could make this manuscript better.

In a word, more well-designed researches with large groups of patients are needed to provide further evidence for the prognostic significance of COX-2 expression in patients with osteosarcoma.
S. He $(\bowtie) \cdot$ Z. Xiao

Department of Oncology, Ganzhou People's Hospital,

Ganzhou 341000, Jiangxi Province, People's Republic of China

e-mail: drshaozhong@126.com

$\mathrm{S} . \mathrm{He} \cdot \mathrm{L}$. Chen

Department of Oncology, Nanfang Hospital of Southern Medical University, Guangzhou 510515, Guangdong Province, People's

Republic of China

G. Zeng

Department of Orthopaedics, Ganzhou People's Hospital,

Ganzhou 341000, Jiangxi Province, People's Republic of China 


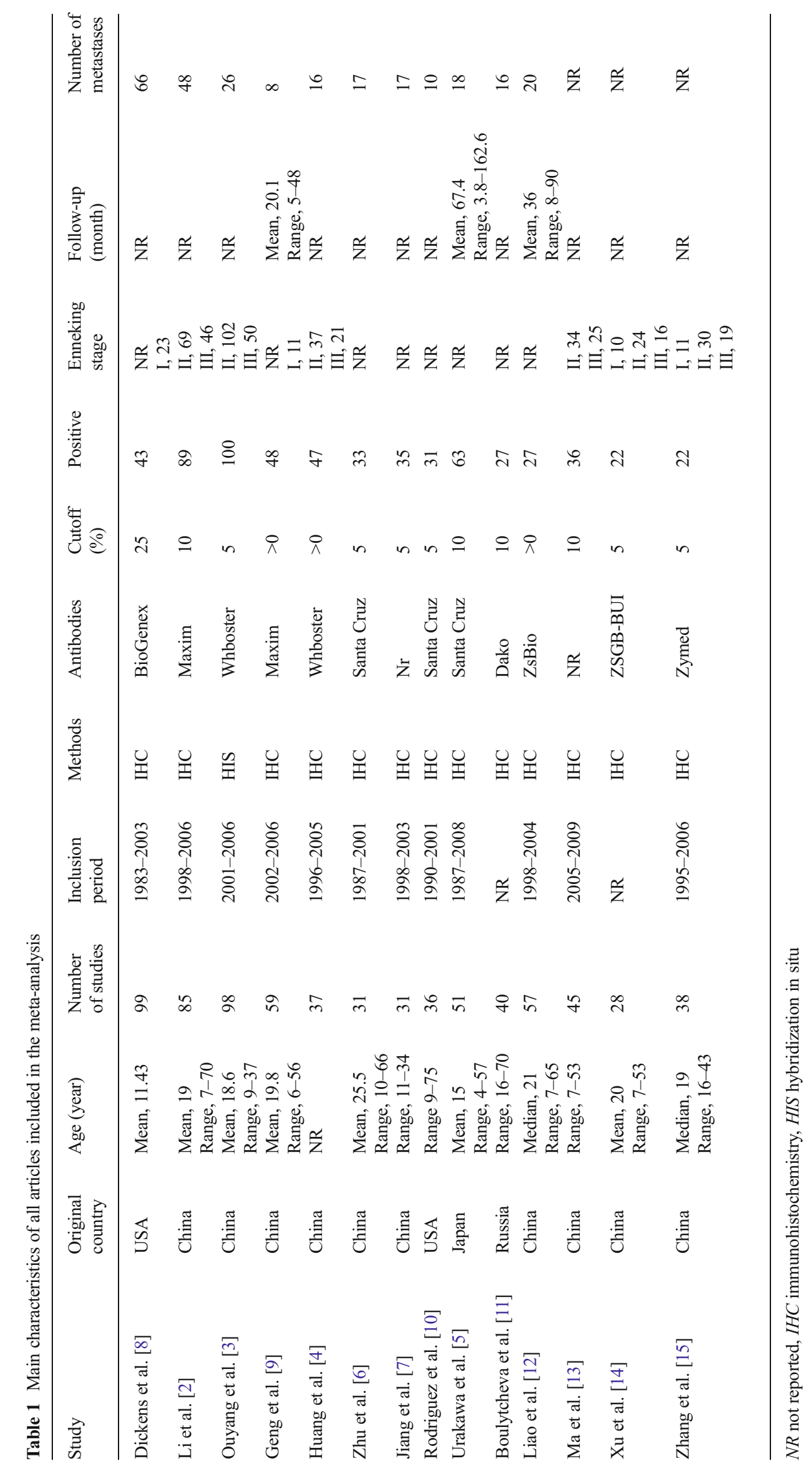




\section{References}

1. Jiao G, Ren T, Lu Q, Sun Y, Lou Z, Peng X, et al. Prognostic significance of cyclooxygenase-2 in osteosarcoma: a meta-analysis. Tumor Biol. 2013;34(5):2489-95.

2. Li Y, Xiao Y, Wang W. Expression of cox-2 and ki-67 in osteosarcoma and their clinical significance. Chin J Gen Pract. 2010;8:274-7.

3. Ouyang Z, Wang S, Kang X, Wang C, Wang J, Guo H. Expression of cyclooxygenase- 2 mRNA, cd105mRNA, and the relation between cyclooxygenase-2mRNA and Cd 105mRNA in osteosarcoma. Chin J Bone Tumor Bone Dis. 2007;6:226-32.

4. Huang J, Shi Y, Xiang Z. The expression of COX-2 in osteosarcoma and its clinical significance. J Med Theor Pract. 2008;21:1134-6.

5. Urakawa $H$, Nishida $Y$, Naruse $T$, Nakashima $H$, Ishiguro $N$. Cyclooxygenase-2 overexpression predicts poor survival in patients with high-grade extremity osteosarcoma: a pilot study. Clin Orthop Relat Res. 2009;467:2932-8.

6. Zhu Y, Chi Y, Wang Y, Fan G. Study of expression and their relationship of COX-2 and MMP-2 in osteosarcoma. J Pract Oncol. 2005;19:91-4.

7. Jiang Y, Yang S, Liu Y. Expression of cyclooxygenase 2 in osteosarcoma and its significance. Cent China Med J. 2004;28:109-10.
8. Dickens DS, Rafal Kozielski R, Leavey PJ, Timmons C, Cripe TP. COX-2 expression does not correlate with outcome in osteosarcoma or rhabdomyosarcoma. J Pediatr Hematol Oncol. 2003;25: $282-5$.

9. Geng Y, Wan C, Chen P. Expressions of COX-2 and HF-1 $\alpha$ and their relationship with clinicopathologic characteristics of osteosarcoma. Tumor. 2008;28:427-30.

10. Rodriguez NI, Hoots WK, Koshkina NV, Morales-Arias JA, Arndt $\mathrm{CA}$, Inwards CY, et al. COX-2 expression correlates with survival in patients with osteosarcoma lung metastases. J Pediatr Hematol Oncol. 2008;30:507-12.

11. Boulytcheva IV, Soloviev YN, Kushlinskii NE, Mahson AN. Expression of molecular markers in the tumor and survival prognosis in osteosarcoma. Bull Exp Biol Med. 2010;150:237-42.

12. Liao Y, Li F, Hu X. Expression and clinical significance of OPN and COX-2 in osteosarcoma. Chin-Ger J Clin Oncol. 2007;6:378-82.

13. Ma J, Chen X, Zhong Y, Li D, Xiao Z. Expression and significance of COX-2 and VEGF in osteosarcoma. Shandong Med J. 2011;51:7-9.

14. Xu X, Huang G, Liu J, Li L, Luo Y. Expression of PTEN, COX-2 and MMP-9 in osteosarcoma and its clinical significance. J Clin Res. 2010;27:820-3.

15. Zhang X, Cai W. Significance of expression of COX-2 and Fas in cases of osteosarcoma. J Clin Exp Med. 2008;7:45-7. 